\title{
Ventilation Solutions in Renovated Apartment Buildings in Cold Climate Conditions
}

\author{
Teet-Andrus Koiv, Alo Mikola, Raimo Simson \\ Department Environmental Engineering, Tallinn University of Technology, Tallinn, Estonia \\ Email: Teet.koiv@ttu.ee
}

Received 25 March 2014; accepted 20 March 2015; published 24 March 2015

Copyright (C) 2015 by authors and Scientific Research Publishing Inc.

This work is licensed under the Creative Commons Attribution International License (CC BY).

http://creativecommons.org/licenses/by/4.0/

c) (i) Open Access

\section{Abstract}

Different solutions of renovating the ventilation in apartment buildings have been researched. The analysis shows that the use of heat recovery in cold climate regions is essential. Central as well as apartment- and room-based solutions with heat recovery have been studied. Balanced ventilation is suitable for small ( 2 - 3-storey) apartment buildings with a suitable room solution for apartments. In larger apartment buildings, the system with the exhaust air heat pump could be used. This is particularly suitable for apartment buildings with mechanical exhaust ventilation. In small apartments, it is most suitable to use room-based air handling units (AHUs) with the recuperative heat exchanger, plus exhaust ventilators in the WC, bathroom and kitchen. The economic indicators of this system are best for two-room apartments. Apartment-based AHUs are suitable for large apartments if there is no opposition from the residents, which is caused by ventilation tubes (ducts) in the apartment. The comparison of the reduced energy cost in case of different AHUs has been presented for small apartment buildings.

\section{Keywords}

AHU, Heat Recovery, Air Change, Energy Calculation for Air Heating, Energy Efficiency of AHU

\section{Introduction}

Member states of the European Union are required to implement energy efficiency measures for buildings according to the Energy Performance of Buildings Directive [1]. With the new building codes, EU member states intend to reduce the total energy consumption in buildings by making them well-insulated and tighter. Due to the tighter and well-insulated constructions, the ventilation loads constitute a growing part of the heating de- 
mand, between $30 \%$ - 60\% for new and retrofitted buildings [2]. As the ventilation heating demand plays an important role in the building's total heating demand, the exhaust air heat recovery is inevitable. It is possible to recover only sensible heat or both sensible and latent heat from the exhaust air [3]-[5]. Energy is used to cover the heat losses due to ventilation air and to move the ventilation air for mechanical ventilation. The main purpose of the study is to compare the different ventilation solutions of apartment buildings and assess their energy consumption.

The ventilation system also influences the air infiltration through the building envelope. A prerequisite for the construction of the mechanical supply-exhaust ventilation is sufficient air tightness of the building. If $\varepsilon_{s t}$ is the temperature ratio of the heat exchanger, in practice only part of the air flows through the heat exchanger [6]. This is the main reason why this phenomenon has been thoroughly studied. Since Kohonen et al. [7] published their experimental and numerical study concerning thermal coupling of leakage air and heat flows in the building envelope, the heat recovery effect between infiltration air and exterior walls has been studied by several authors, for example, [8]-[10]. In several countries, the air tightness of the building envelope is determined according to the type of the ventilation system. If the supply and exhaust airflows are balanced, the proportion of the infiltration is higher than in the case when the room is positively or negatively pressurized. According to studies carried out in the UK [11], there is no considerable infiltration in case of exhaust air ventilation and building leakage rate $n_{50}=3 \mathrm{~h}^{-1}$. Almost all the air passes through the exhaust fan.

The paper presents the results of the investigations into the indoor climate and energy efficiency of different ventilation systems in residential buildings. The main types of ventilation in cold climate conditions are natural ventilation, mechanical exhaust ventilation, mechanical exhaust ventilation with exhaust air heat pump heat recovery, supply-exhaust ventilation with the apartment-based ventilation unit, and supply-exhaust ventilation with the room-based ventilation unit. The performances of the different ventilation systems in low-energy residential houses have been earlier presented by Maier et al. [12]. The energy performance of heat recovery units has been investigated by Jaber et al. [13] and Laverge et al. [14]. Ventilation heat recovery in residential buildings has been investigated by Dodoo et al. [15]. A number of studies on the ventilation and indoor air quality in apartment buildings have been carried out at Tallinn University of Technology by Mikola and Koiv [16]-[19].

The current research was conducted in 60 degrees of latitude (Estonia), where winter air temperatures drop to $-20^{\circ} \mathrm{C}$ or even lower. In these circumstances, efficient AHUs with heat recovery are necessary.

\section{Method}

To determine the effectiveness of various systems the following formulas are used. The thermal energy consumption for air heating is calculated based on the following correlation

$$
Q=H \cdot S \cdot 24 \cdot\left(1-\eta_{Q}\right) \cdot 10^{-3} \mathrm{MWh}
$$

where $H$-specific heat consumption for air change, $\mathrm{kW} / \mathrm{K} ; \mathrm{S}$ - the number of degree days, $\mathrm{d}{ }^{\circ} \mathrm{C}$, determined by the balance temperature of the building; $\eta_{Q}$ —energy ratio for AHU, determined considering the location of the building and the temperature ratio of AHU. Specific heat consumption for air change is calculated by (2)

$$
H=L \cdot \rho \cdot c \mathrm{~kW} / \mathrm{K}
$$

where $L$-air flow rate $\mathrm{m}^{3} / \mathrm{s}$, average per day; $\rho$-density of the air, $\mathrm{kg} / \mathrm{m}^{3} ; c$-specific heat of the air, $(\mathrm{kJ} / \mathrm{kg} \cdot \mathrm{K})$.

To determine the airflow rates, the demand-driven principle of AHU and the resulting airflow rates are taken into account. Electric energy consumption for heating the air is determined by (3)

$$
E_{1}=\Phi \cdot z \cdot 10^{-3} \mathrm{MWh}
$$

where $\Phi$-power of electric heating coil, $\mathrm{kW} ; \mathrm{z}$ —working hours, h.

The electrical energy consumption of the fans of AHU with air piping is determined by the presumed SFP factor.

$$
E_{2}=L \cdot \mathrm{SFP} \cdot z \cdot 10^{-3} \mathrm{MWh}
$$

where SFP — specific ventilator power, $\mathrm{kW} /\left(\mathrm{m}^{3} / \mathrm{s}\right)$.

To determine the reduced energy consumption, the correction factor of electricity consumption 1.5 is considered. 
The calculations were made in small apartments $\left(50 \mathrm{~m}^{2}\right)$.

\section{Results}

\subsection{Natural Ventilation}

Ventilation in old apartment buildings, as a rule, is natural.

Figure 1 shows two typical solutions of natural ventilation: the one on the left for typical 9-storey apartment buildings and the one on the right for typical 5-storey apartment buildings.

Natural ventilation operates due to the difference in the air density indoors and outdoors. Additional influence is exercised by the height of the ventilation channels and the strength of the wind.

Natural ventilation is unstable in operation. During the periods of transition, especially in the summer, the air change is not sufficient, but it is often too intensive during the winter period, especially at low ambient temperatures.

\subsection{Indoor Climate}

In apartment buildings the most serious problems caused by partial renovation are the facts that the walls and the roofs have been insulated and the windows have been replaced, but the ventilation has not been renovated.

Some examples of indoor climate in partly renovate department buildings are given.

In the bedrooms of partly renovated apartment buildings very high relative humidity is observed, as can be seen in the Figure 2(a). Figure 2(b) shows the level of carbon dioxide concentration in the bedrooms of a partly renovated apartment building. It can be seen that the $\mathrm{CO}_{2}$ level extends to $3000 \mathrm{ppm}$.

The formation of mold in the region of thermal bridges in apartments is quite common if the relative humidity is high.

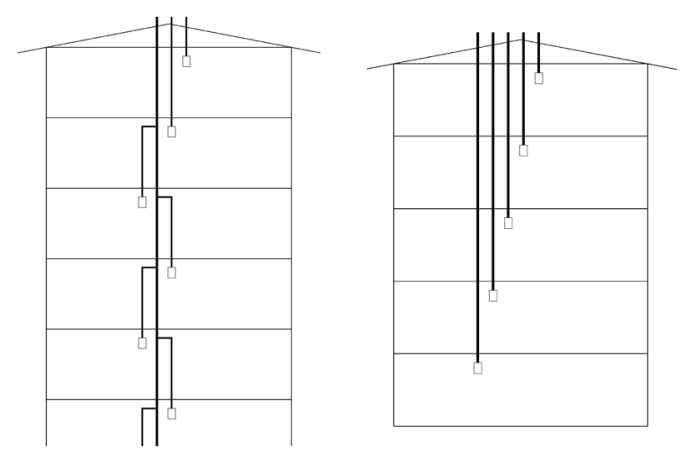

Figure 1. Solutions of natural ventilation for typical old apartment buildings.

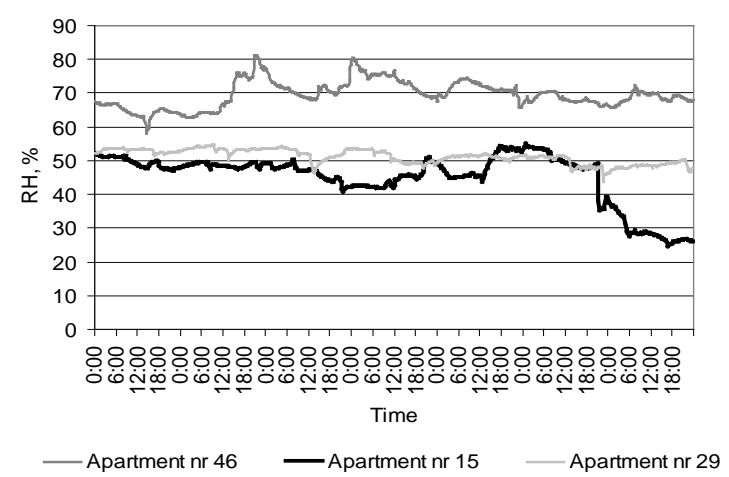

(a)

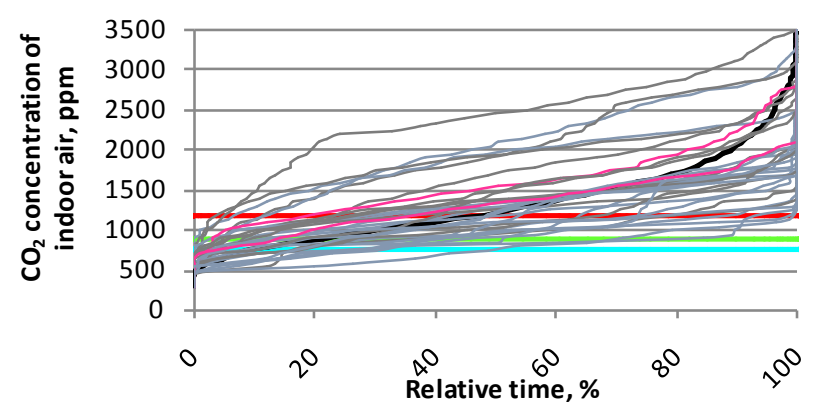

(b)

Figure 2. Relative humidity (left) and carbon dioxide concentration level (right) in the bedrooms of a partly renovated 60 -apartment building in the winter time. 


\subsection{Ventilation Solutions}

It should be noted that there novation of ventilation in old apartment buildings is quite complicated. It is very difficult to ensure the required air change with the ventilation systems, the solution of which is acceptable for the tenants.

1) Natural ventilation with fresh air valves, Figure 3

With that solution residents sometimes complain that fresh air valves cause cold air currents in rooms. A better solution is to use special heating coils, which are combined with fresh air valves.

The main disadvantages:

- High specific consumption of heat energy;

- At maximum loads the runoff of pollutants is not guaranteed;

- Air change is unstable: in practice there is no air change in summer, but in winter the air change is too high;

- Possible inconveniences of cold air inflow in the living space;

- External noise and pollution are carried indoors;

- At the maximum loads good indoor climate is not guaranteed for the majority of the year.

Good qualities:

- Absolutely no noise;

- Minimal investments.

The approximate annual specific reduced energy consumption is 2.5 MWh per year if the air change rate $\mathrm{n}=$ $0.57 \mathrm{~h}^{-1}$.

2) Mechanical exhaust ventilation

This is used in a newer type of apartment buildings (built between 1990-2012), Figure 4. This system ensures good air change and air quality, but is very expensive in operating costs. The air heating cost in such a system is about $50 \%-70 \%$ of the heating costs. The approximate annual specific reduced energy consumption is 3.7 MWh per year.

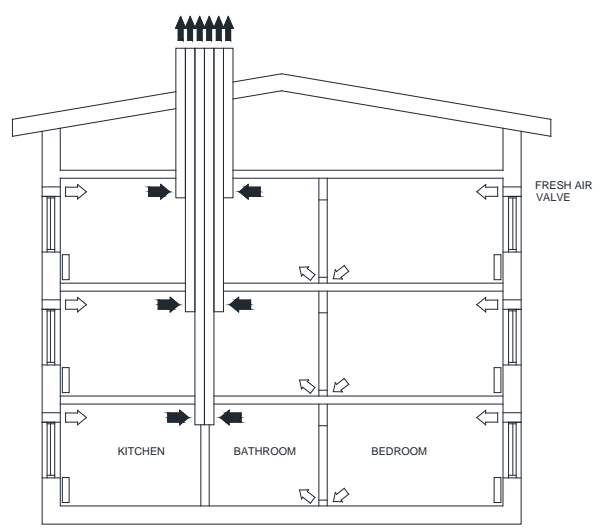

Figure 3. Natural ventilation with fresh air valves.

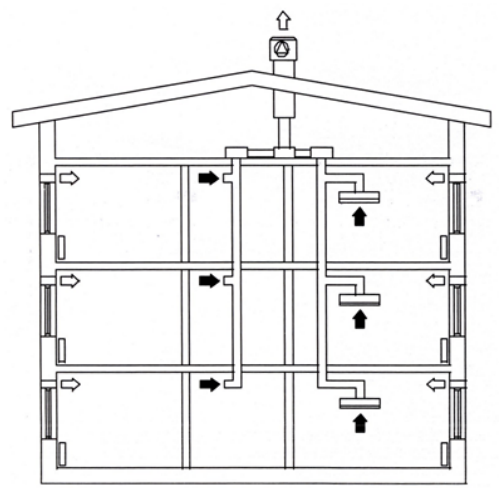

Figure 4. Solution with mechanical exhaust ventilation. 
The main disadvantages:

- Energy consumption is greatest;

- Possible unpleasantness of cold air inflow in the living space;

- External noise and pollution are carried indoors;

- The maximum loads for ensuring good indoor climate will increase.

Good qualities:

- Compared with natural ventilation, stable air change is guaranteed throughout the year.

The following solutions have heat recovery.

3) The apartment air handling unit

Figure 5 shows the ventilation solution with the apartment air handling unit (AHU).

The main disadvantages:

- For a small apartment it is relatively expensive;

- Expenditure on exchanging filters.

Good qualities:

- Ensures very good indoor air quality;

- In large apartments it is also economically justified.

It is widely used in detached houses as well as new apartment buildings. It is problematic to use in old apartment buildings as people do not like installing ducts in the flat. The approximate annual specific reduced energy consumption is 1.9 MWh per equivalent apartment if SFP = 2 for small apartments and 2.5 MWh for large apartments.

4) The use of central balanced ventilation, Figure 6

The main disadvantages:

- Ventilation air ducts in the apartment;

- AHU and air ducts on the staircase;

- The risk of noise;

- Requires very good design and construction;

- Problems with duct installation and sometimes with noise;

- Expenditure on exchanging filters in the AHU.
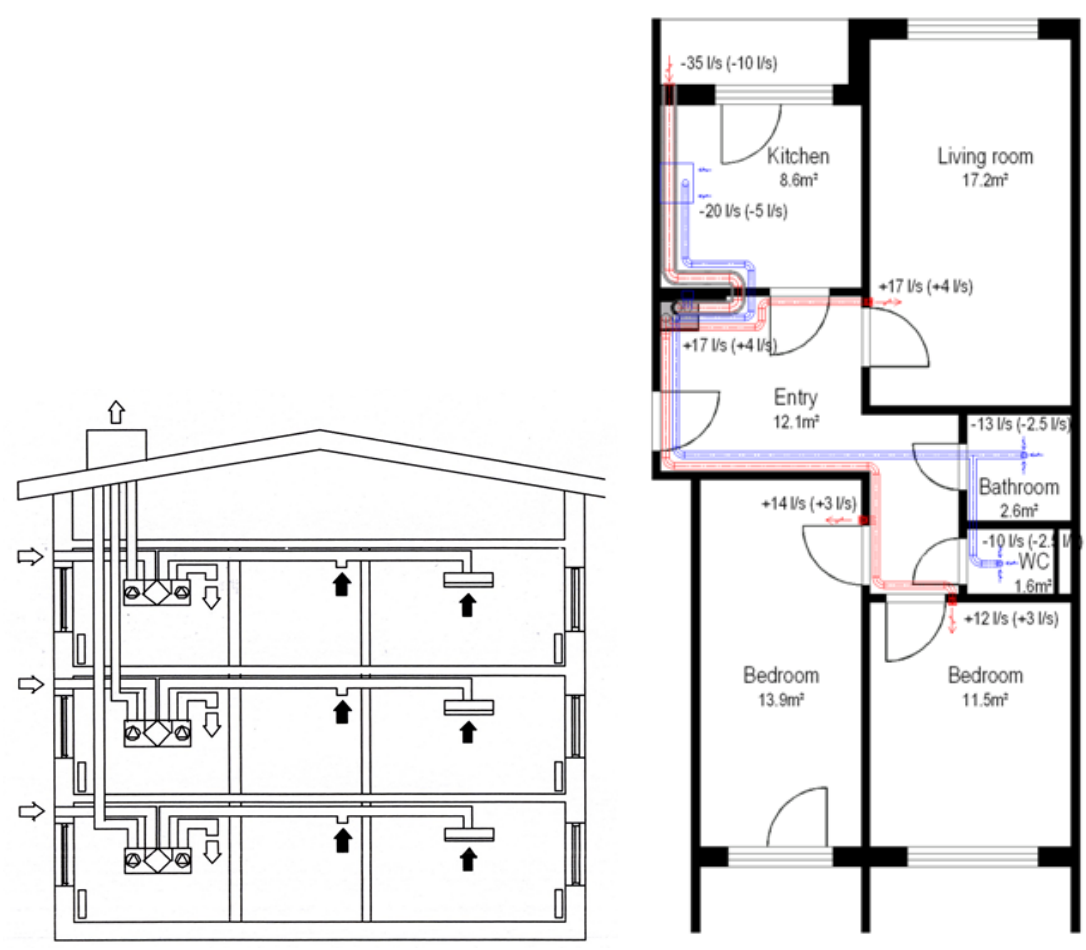

Figure 5. Principal solution (left) and apartment plan (right) of apartment solution. 
Good qualities:

- Ensures very good air quality;

- Suitable for small (2 - 3-storey) apartment buildings with a suitable space solution of the apartment.

In practice it is possible to use central balanced ventilation in smaller apartment buildings, installing AHU and ventilation ducts on the staircases. The annual reduced energy consumption is 2.0/2.6 MWh per equivalent apartment if SFP $=2.5$ (small/large apartments).

5) The use of the room AHU and programmable exhaust ventilators in the WC, bathroom and kitchen 7.

Ventilation solution with the room AHU has recuperative heat recovery (for example Meltem AHU) Figure

When testing Meltem AHU, Figure 10, in the range of outdoor air temperature from +5 to $-20^{\circ} \mathrm{C}$, the average temperature ratio (efficiency) was between $40 \%$ to $65 \%$, with an average of $60 \%$. In Figure 8 we can see the temperature ratios of Meltem AHU with the 3rd speed.

The main disadvantages:

- At the ambient temperature of below $-18^{\circ} \mathrm{C}$ the frost protection device turns the unit off;

- AHU $410 \times 390 \mathrm{~mm}$ is in the living room;

- Additional costs on exchanging filters;

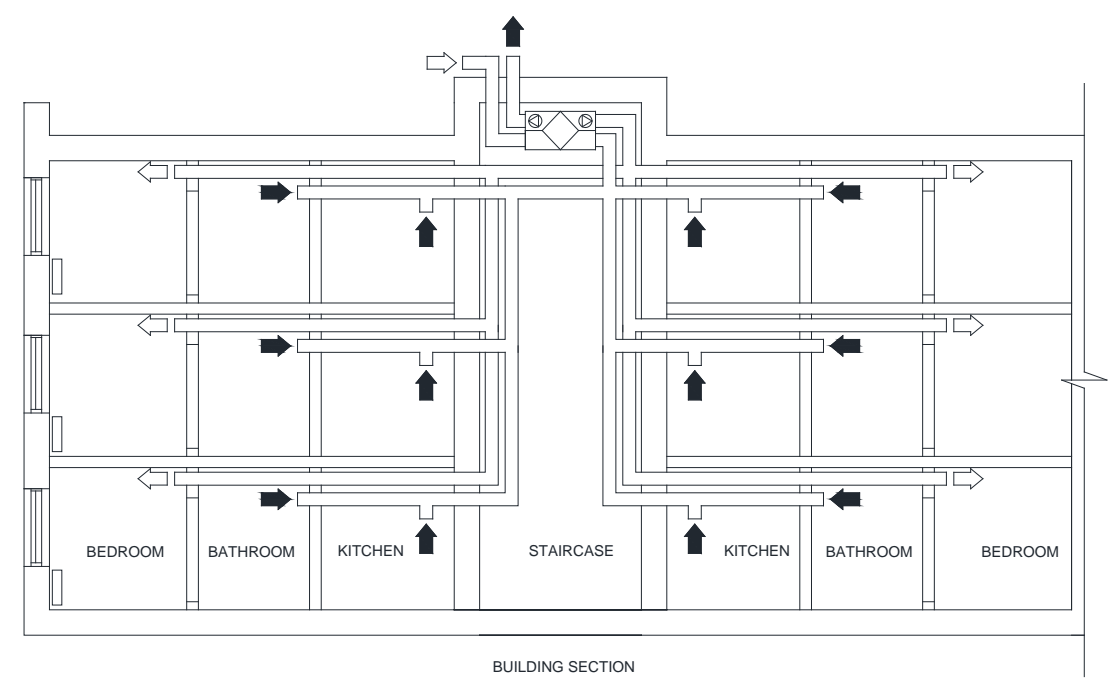

Figure 6. Central balanced ventilation.
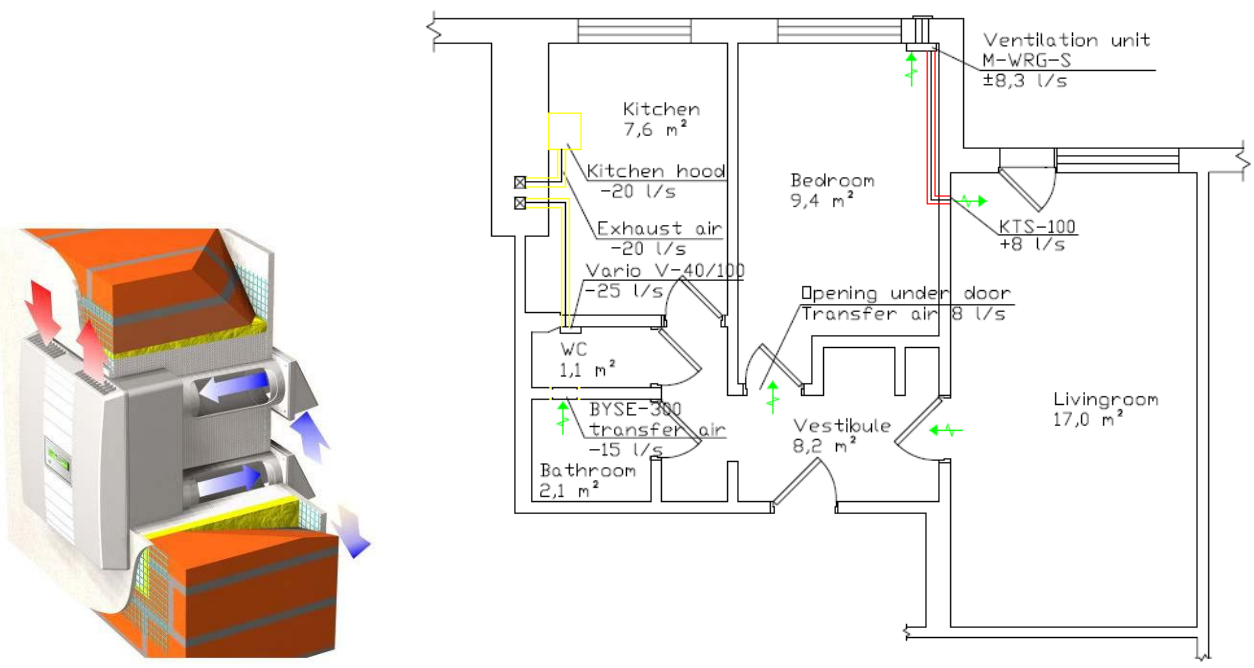

Figure 7. Ventilation solution with the room AHU (Meltem) installed in a 2-room apartment. 
- At night with restrictive noise limits the guaranteed air flow rate is up to $40 \mathrm{~m}^{3} / \mathrm{h}$.

Good qualities:

- Demand-based ventilation with heat recovery is guaranteed;

- Good economic indicators for small apartment buildings.

The approximate annual specific reduced energy consumption is $1.3 \mathrm{MWh}$ per equivalent small apartment (1.9 MWh-for large apartments).

It would be practical to ensure central exhaust ventilation from the WC, bathroom and kitchen during the time when they are not used with the pressure controlled exhaust ventilation system (on the roof).

Tenants' evaluation of the use of Meltem AHU in apartments has been very positive.

6) The exhaustair heat pump system

The principal diagram of the unit is shown in Figure 9. Fresh air is sent to rooms through fresh air valves.

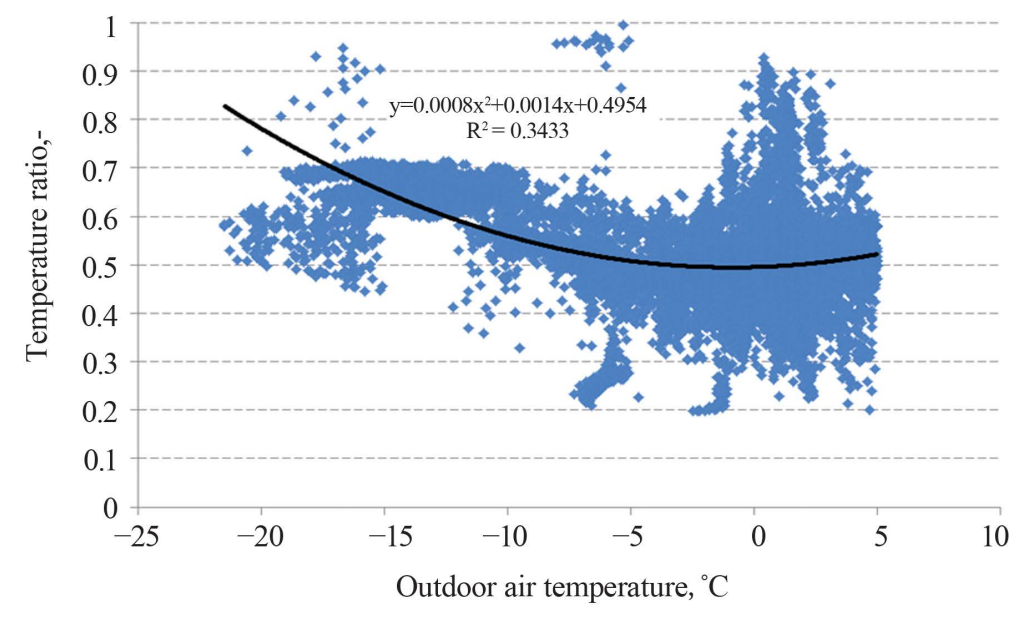

Figure 8. Temperature ratios of Meltem AHU.

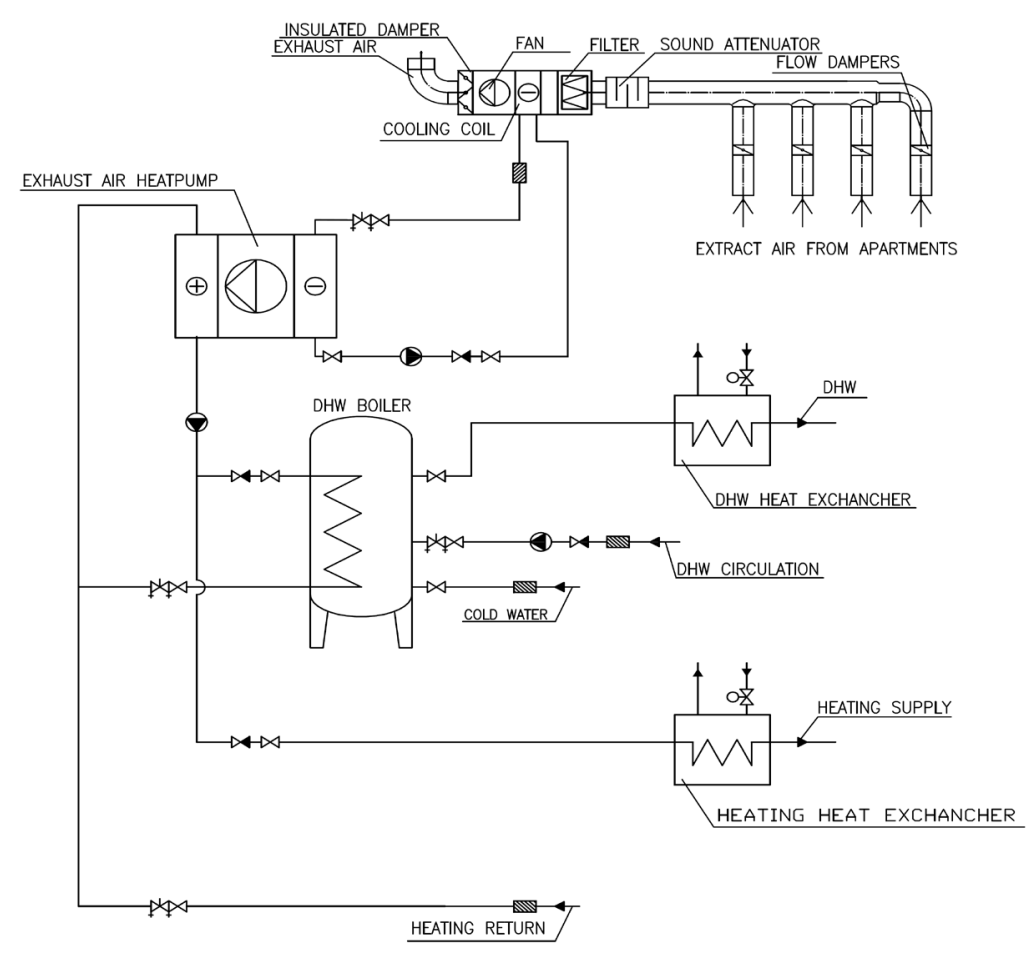

Figure 9. Principal diagram of the exhaust air heat pump. 
The mechanical exhaust ventilation system together with cooling batteries allows using the thermal potential of the exhaust air.

The main disadvantages:

- Requires very good design, construction, adjustment of the airflows, and maintenance;

- With the maximum pollution loads of the WC, bathroom and kitchen it is difficult to ensure the necessary air change;

- It is possible that there is some unpleasantness of cold air inflows in the living rooms;

- Outside noise and pollution are carried indoors;

- Requires the existence of ventilation flues, which are at least in a satisfactory condition;

- For efficient operation of the heat pump, the heating system must have a reduced temperature graph;

- The payback time of investments is relatively long;

- It is necessary to adjust the exhaust ventilation airflows in the apartments;

- In cogeneration districts during the summer period the energetic feasibility is questionable;

- Additional costs of exchanging filters.

Good qualities:

- The construction work in the apartments is relatively small;

- The annual distribution of the heat production of the heat pump and district heating and the share of electricity in the studied building can be seen in Figure 10;

- The average COP was 2.6 and the share of heat production of the heat pump was $47.3 \%$.

In summer the share of the heat pump in the heat supply of the building was about $90 \%$, the COP was 3.1 .

The approximate annual specific reduced energy consumption is $2.3 \mathrm{MWh}$ per equivalent small apartment (3.0 MWh-for large apartments).

7) Room-based regenerative AHU

Figure 11 shows the room AHU with regenerative heat recovery. This AHU has a regenerative ceramic heat exchanger. This is a paired device, each of which is typically located in a separate room. They operate intermittently, the air flows out for $70 \mathrm{~s}$ and in for $70 \mathrm{~s}$. One of the devices provides the room with fresh air, the other removes the exhaust air, the latter also heats up the ceramic heat exchanger. The device has a very small ventilator. It should be noted that in laboratory conditions, where the regenerative AHU was tested, the system worked well. In practical operating conditions in an apartment where in addition to the room AHU there is natural exhaust ventilation from the WC/bathroom and the kitchen, the efficiency of the system is very low. It should be noted that the intensity of natural ventilation plays an important role, Figure 12.

The main disadvantages:

- The risk of noise is very high;

- Outside noise and pollution are carried indoors;

- Its operation is directly dependent on working natural ventilation;

- In designing it is difficult to achieve effective functioning of the AHU on the lower and middle floors of the buildings and therefore, during the colder months there is practically no heat recovery. Thus the suitability of the fan characteristic must be considered;

- Inconveniences of the cold air inflow into the living rooms.

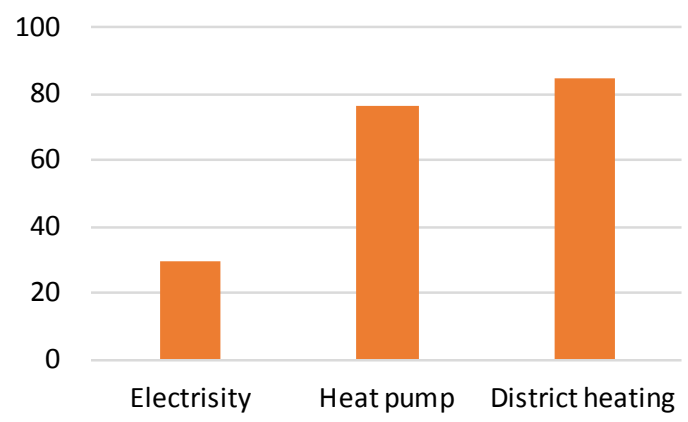

Figure 10. The annual distribution of the heat output of the heat pump and district heating, the share of electricity, in MWh. 


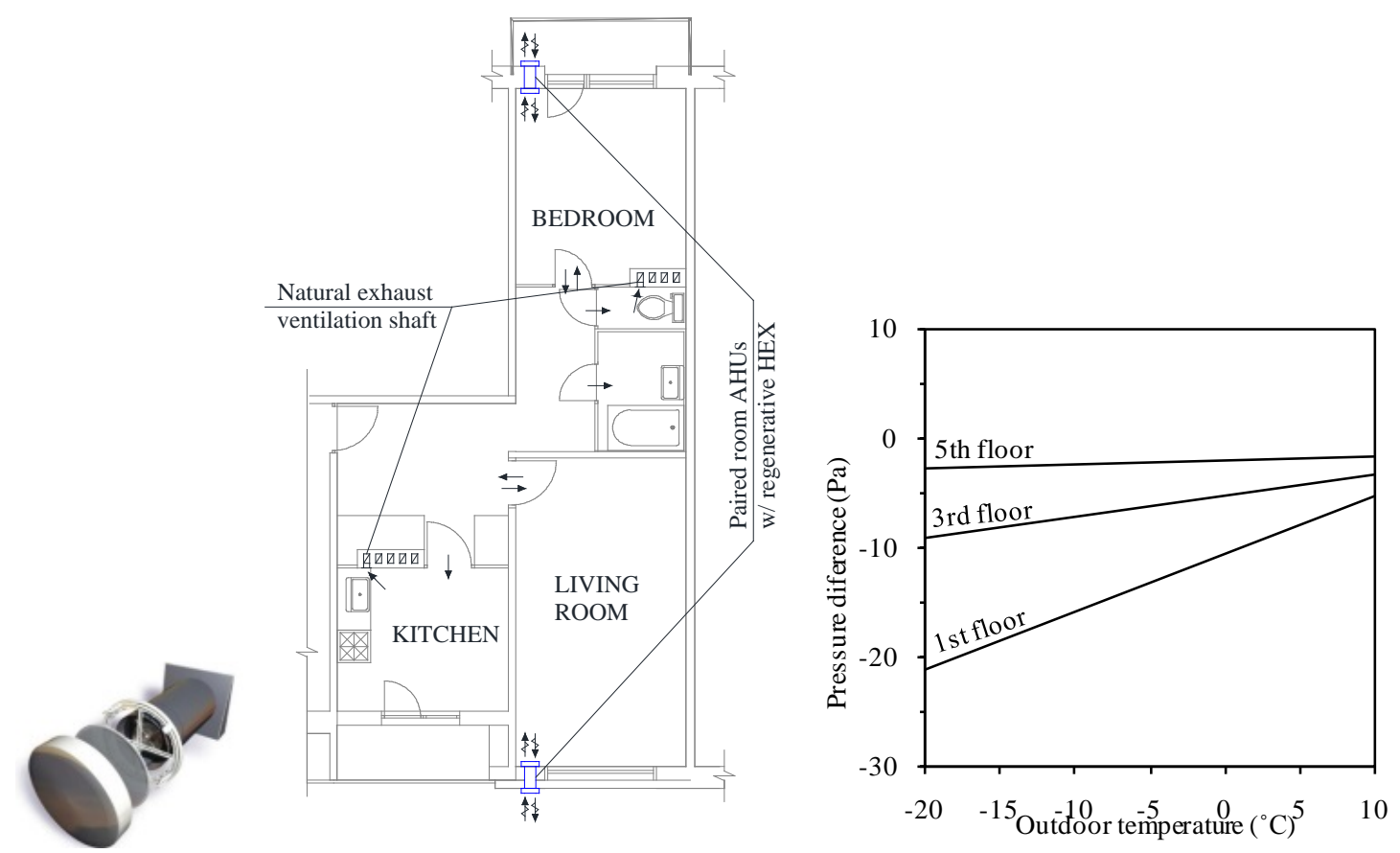

Figure 11. Room AHU with regenerative heat recovery (left), apartment plan with the regenerative AHU (middle) and differential pressure in apartments on the different floors of the building with natural ventilation (right).

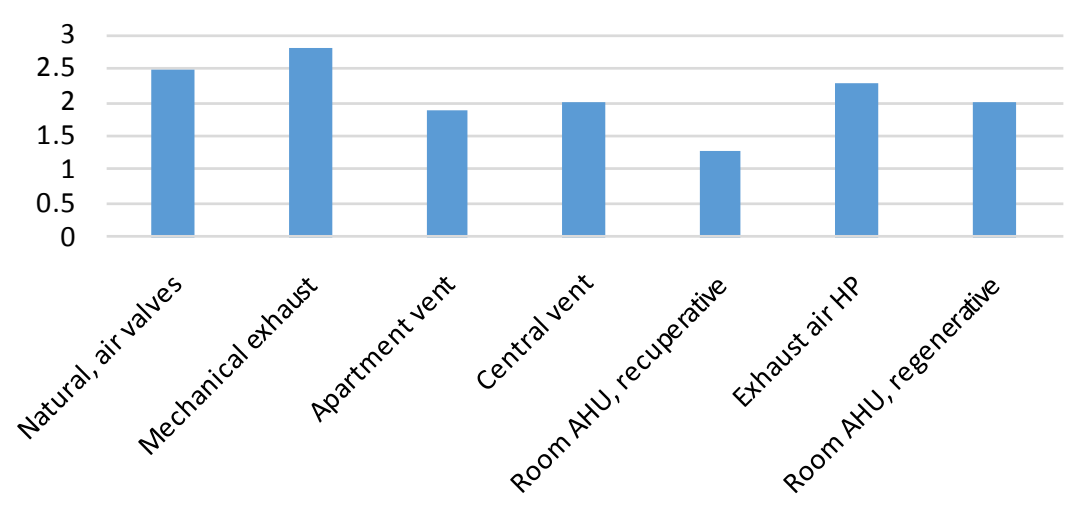

Figure 12. Comparison of the reduced energy consumption (MWh) of different ventilation solutions for small $\left(50 \mathrm{~m}^{2}\right)$ apartments.

Good qualities:

- Suitable for low, 1 - 2-storey buildings;

- The approximate annual specific reduced energy consumption is 2.1 MWh per equivalent small apartment (3.0 MWh_for large apartments).

\subsection{Comparison of the Reduced Energy Consumption of Different Ventilation Solutions}

The comparison of the reduced annual energy consumption of the different ventilation solutions for small (50 $\left.\mathrm{m}^{2}\right)$ apartments is shown in Figure 12.

In small apartments the energy consumption is lowest with the recuperative room based AHU. In other systems, with heat recovery, however, it is similar. Thus, when making a choice, the characteristics of the system have to be considered, as the investments are quite similar for heat recovery systems, approximately $€ 1000$ $€ 1200$ for small apartments. In large apartments, the investments in room-based systems are 2 times higher. In this situation, it is preferable to use centralized systems or the apartment AHU. 


\section{Conclusions}

The results of the study show that in the renovation of old apartment buildings, solutions with heat recovery must be used. However, the economic indicators of the solutions are somewhat different for small and large apartments.

In small apartments, it is suitable to use room-based solutions with recuperative heat recovery units, particularly in small and medium-sized buildings. In large apartments, apartment-based AHUs would be both technically and economically perfect, provided that they are accepted by the residents.

In smaller 2 - 3-storey buildings, very good air quality and economic characteristics can be achieved with the central balanced ventilation system.

Despite some shortcomings of the system and the complexity, the exhaust air heat pump system could be used in renovating the ventilation in large apartment buildings. This solution is especially suitable for apartment buildings with mechanical exhaust ventilation.

When renovating the ventilation in old apartment buildings, it is necessary to pay special attention to the design, quality construction and supervision. Adjusting and maintaining the system are of great importance.

\section{Acknowledgements}

The research was supported by the Estonian Research Council, with Institutional research funding grant IUT115 and with the project "Development of efficient technologies for the air change and ventilation necessary for the increase in the energy efficiency of buildings, AR12045", financed by SA Archimedes. The publication of this article was supported by ESFmeasure 1.2.4 Development of cooperation and innovation in universities, the sub-measure "Doctoral Schools" that finances the project "Construction and Environmental Engineering PhD School”-project code1.2.0401.09-0080.

\section{References}

[1] European Commission (2007) 2020 Vision: Saving Our Energy. https://www.energy.eu/publications/2007_eeap_en.pdf

[2] Gustavsson, L., Dodoo, A. and Sathre, R. (2011) Impact of Ventilation Heat Recovery on Primary Energy Use of Apartment Building Built Conventional and Passive House Standard. World Renewable Energy Congress, Linköping, May 2011, 8-11.

[3] Diemanu, J., Roth, K.W. and Brodrick, J. (2003) Air-to-Air Energy Recovery Heat Exchangers. ASHRAE Journal, 45, 57-58.

[4] Fouih, Y.E., Stabat, P., Riviere, P., Hoang, P. and Archambault, V. (2012) Adequacy of Air-to-Air Heat Recovery Ventilation System Applied in Low Energy Buildings. Energy and Buildings, 54, 29-39. http://dx.doi.org/10.1016/j.enbuild.2012.08.008

[5] Mikola, A., Kõiv, T.-A. and Voll, H. (2014) Ventilation of Apartment Buildings and Nursing Homes. Smart Grid and Renewable Energy, 5, 107-119. http://dx.doi.org/10.4236/sgre.2014.55010

[6] Heidt, F.D. (2006) Ventilation for Energy Efficient Buildings. ISES Summer Workshop.

[7] Kohonen, R., Kokko, E., Ojanen, T. and Virtanen, M. (1985) Thermal Effects of Air Flow in Building Structures. Technical Research Centre of Finland, Research Reports 367, Espoo.

[8] Virtanen, M. (1993) Thermal Coupling of Leakage Air and Heat Flows in Buildings and in Building Components. Ph.D. Thesis, Technical Research Centre of Finland, HVAC-Laboratory, Espoo.

[9] Buchanan, C. and Sherman, M.A. (2000) Mathematical Model for Infiltration Heat Recovery. Lawrence Berkley Laboratory Report, LBL-44294, Berkley.

[10] Qiu, K. and Haghighat, F. (2007) Modeling the Combined Conduction-Air Infiltration through Diffusive Building Envelope. Energy and Buildings, 39, 1140-1150. http://dx.doi.org/10.1016/j.enbuild.2006.11.013

[11] Lowe, R.J. (2000) Ventilation Strategy, Energy Use and $\mathrm{CO}_{2}$ Emissions in Dwellings-A Theoretical Approach. Building Services Engineering Research and Technology, 21, 179-185. http://dx.doi.org/10.1177/014362440002100306

[12] Maier, T., Krzaczek, M. and Tejchman, J. (2009) Comparison of Physical Performances of the Ventilation Systems in Low-Energy Residential Houses. Energy and Buildings, 41, 337-353. http://dx.doi.org/10.1016/j.enbuild.2008.10.007

[13] Jaber, S. and Ajib, S. (2012) Energy Recovery System in Mediterranean Region. Sustainable Cities and Society, 3, 24-29. http://dx.doi.org/10.1016/j.scs.2012.01.002

[14] Laverge, J. and Janssens, A. (2012) Heat Recovery Ventilation Operation Traded off against Natural and Simple Exhaust Ventilation in Europe by Primary Energy Factor, Carbon Dioxide Emission, Household Consumer Price and Ex- 
ergy. Energy and Buildings, 50, 315-323. http://dx.doi.org/10.1016/j.enbuild.2012.04.005

[15] Dodoo, A., Gustavsson, L. and Sathre, R. (2000) Primary Energy Implications of Ventilation Heat Recovery in Residential Buildings. Energy and Buildings, 31, 37-47.

[16] Koiv, T.A., Mikola, A. and Kuusk, K. (2012) Energy Efficiency and Indoor Climate of Apartment Buildings in Estonia. International Journal of Energy Science, 2, 94-99.

[17] Koiv, T.A., Voll, H., Mikola, A., Kuusk, K. and Maivel, M. (2010) Indoor Climate and Energy Consumption in Residential Buildings in Estonian Climatic Condition. WSEAS Transactions on Environment and Development, 6, $235-244$.

[18] Mikola, A. and Koiv, T.A. (2011) Indoor Air Quality in Apartment Buildings of Estonia. Computers and Simulation in Modern Science: Selected Papers from WSEAS Conferences, 257-261.

[19] Koiv, T.A. (2007) Indoor Climate and Ventilation in Tallinn School Buildings. Proceedings of the Estonian Academy of Sciences, Engineering, 13, 17-25. 